\title{
Congestion Management under Restructured System Environment
}

\author{
Ashwini Thakre', S.R. Gawande ${ }^{2}$ \\ Department of Electrical Engineering, K.D.K.C.E., Nagpur, India ${ }^{1,2}$
}

\begin{abstract}
The success of privatization of most of the industries led people to think for the deregulation of electric power system. This results in restructuring of currently vertically integrated utility (VIU) to the different zones. Due to this worldwide deregulation or privatization process, the electricity industry has undergone drastic changes and has significantly affected energy markets. In a deregulated power market, the optimum power flow (OPF) for an interconnected grid system is an important concern as related to transmission loss and operating constraints of power network. The increased power transaction as related to increased demand and satisfaction of those demand to the competition of generation companies (GENCOs) are resulting the stress on power network which further causes the danger to voltage security, violation of limits of line flow, increase in the line losses, large requirement of reactive power, danger to power system stability and over load of the lines i.e. congestion of power in system. More often than not, pool market results originate network congestion in the transmission lines which is one of the technical problems that appear particularly in the deregulated environment. This paper reviews some of congestion management (CM) methods including generator rescheduling, FACTS devices and demand response. Each technique has its own significance and potential for management of congestion in a deregulated power system.
\end{abstract}

Keywords: Congestion, power system deregulation, generator rescheduling, FACTS devices, demand response.

\section{INTRODUCTION}

The restructuring of power system contains the paradigm shift in power grids control activities. The deregulation of power network has caused a large usage of the transmission grids. Here mostly, power network operates at the rated capacity as market players maximize the profit by using as much as of existing transmission resources. The increased trend in the number of contracts signed for the electricity market trades and availability of less no. of transmission resources leads to power network congestion. Real-time transmission congestion is considered as the operating condition for which there is not sufficient transmission capability to employ all traded transactions at same time due to few unexpected contingencies. The contingency constraints can be generator outage, sudden increase of load demand, or failure of equipments. It is found that voltage limit violation and line loading limit violation have been responsible for several incidents of major network collapses leading to partial or even complete blackouts. The transmission lines or transformers' overloading condition is called congestion. In the restructuring era, the task of independent system operator (ISO) is the congestion free power system.

Congestion may be caused due to various reasons, such as transmission line outages, generator outages, and change in energy demand. Other reason, due to which congestion problem has increased in recent years, are as follows:-

- Deregulation of power industry has caused the electricity price to be lower, better service quality and electricity in bulk can be sent across-border in competitive electricity markets. Such transmission of bulk power may cause the electricity networks to reach their physical limits.

- In deregulated environments, if transmission capacity is not enough then there is a lack of investment I electricity networks in order to meet the demand and generation. Or, it can be said that transmission capacity relative to peak load, has become less in many countries.

- Due to the integration of wind generation into electricity transmission networks, it is difficult to manage congestion because of fast changing power flows of electricity networks caused by wind power fluctuations.

This paper is an attempt to review the different methods to remove congestion in transmission under restructured system environment.

\section{CONGESTION MANAGEMENT}

In this, the system is split into the three different pricing areas. Spot market bidders have to submit separate bids for each price area in which they have generation or load. If no congestion occurs during market settlement, the market will 


\section{ISO 3297:2007 Certified}

Vol. 5, Issue 4, April 2017

be stable at one price which will be same as if no price area existed. If congestion does occur, price areas separately settled at prices that satisfy transmission limitations. Areas with higher generation have lower prices and area with higher load have higher prices.

Congestion in power system network is a problem that occurs in a deregulated scenario and provides hindrance in the free flow of quality power and safe operation of power system.

\section{CONGESTION MANAGEMENT METHODOLOGIES}

- Generator Rescheduling

- FACTS Devices

- Demand Response

\section{A. Generator Rescheduling}

In generation rescheduling, sufficient numbers of the least expensive generators are selected first to meet system predicted demands and the market-clearing price is determined by the most expensive bid that has been accepted. Next, ISO will check whether there are constraint violations or not and if there are, it would execute a generation re-dispatch. System operator re-dispatches power generation in such a way that resulting power flows does not overload any line.

There are two methods for the congestion management using generator rescheduling:

1) The numerical methods

2) Artificial intelligent techniques

The problem that faces power industry is how to determine which method is most suitable for a power system analysis. In power flow analysis, high degree accuracy and a faster solution time are required to determine which method is best to use. After reviewed various work, this paper gives an idea about the best method for the congestion management.

1) The Numerical Methods

Numerical methods are techniques by which mathematical problems are formulated so that they can be solved with arithmetic operations and they usually provide only approximate solution. For the past three decades, various numerical analysis methods have been applied in solving load flow analysis problems. Also with the industrial developments in the society, the power system kept increasing and the dimension of load flow equation also kept increasing to several thousands. With such increases, any numerical mathematical method cannot converge to a correct solution. Thus power engineers have to seek more reliable methods. The numerical method provides an approach to find solution with the use of computer, therefore there is need to determine which of the numerical method is faster and more reliable in order to have best result for load flow analysis. The most commonly used iterative methods are:

- Gauss-Seidel method

- Newton-Raphson method

- Fast Decoupled method

2) Artificial Intelligent Techniques

Commonly, artificial intelligence is known to be the intelligence exhibited by machines and software, for example, robots and computer programs. The term is generally used to the project of developing systems equipped with the intellectual processes features and characteristics of humans, like the ability to think, reason, find the meaning, generalize, distinguish, learn from past experience or rectify their mistakes. Artificial general intelligence (AGI) is the intelligence of a hypothetical machine or computer which can accomplish any intellectual assignment successfully which a human being can accomplish.

This includes artificial intelligent techniques for example differential evolution, firefly algorithm, particle swarm optimization, genetic algorithm, fuzzy system and hybrid approaches.

\section{B. FACTS Devices}

The FACTS concept is based on the substantial incorporation of power electronic devices and methods into the highvoltage side of the network, to make it electronically controllable (IEEE / CIGRE, 1995). Many of the ideas upon which the foundation of FACTS rests evolved over a period of many decades. Nevertheless, FACTS, an integrated philosophy, is a novel concept that was brought to fruition during the 1980's at the Electric Power Research Institute 


\section{ISO 3297:2007 Certified}

Vol. 5, Issue 4, April 2017

(EPRI), the utility arm of North American utilities. FACTS looks at the ways of capitalizing on many breakthroughs taking place in the area of high-voltage and high current power electronics, aiming at increasing the control of power flows in the high voltage side of the network during both steady-state and transient conditions. Power electronic devices have had a revolutionary impact on the electric power systems around the world. The availability and application of Thyristors have resulted in a new breed of Thyristor-based fast operating devices devised to control and switching operations. The below chapter deals with the basic operating principles of FACTS devices and provides detailed discussions about the structure, operation, and modelling of the TCSC and the UPFC.

FACTS controllers can be broadly divided into four categories, which includes

- Series controllers

- Shunt controllers

- Combined series-series controllers

- Combined series-shunt controllers

1) Thyristor Controlled Series Compensator (TCSC):

Thyristor-controlled series capacitor (TCSC) is a capacitive reactance compensator, which consists of a series capacitor bank shunted by a thyristor controlled reactor in order to provide a smoothly variable series capacitive reactance. Even though a TCSC in the normal operating range is mainly capacitive, but it can also be used in an inductive mode. The power flow over a transmission line can be increased by controlled series compensation with minimum risk of sub synchronous resonance (SSR). CSC is a second generation FACTS controller, which controls the impedance of the line in which it is connected by varying the firing angle of the thyristors. A TCSC module comprises a series fixed capacitor that is connected in parallel to a thyristor controlled reactor (TCR) i. e. Shown in Fig.2.1.

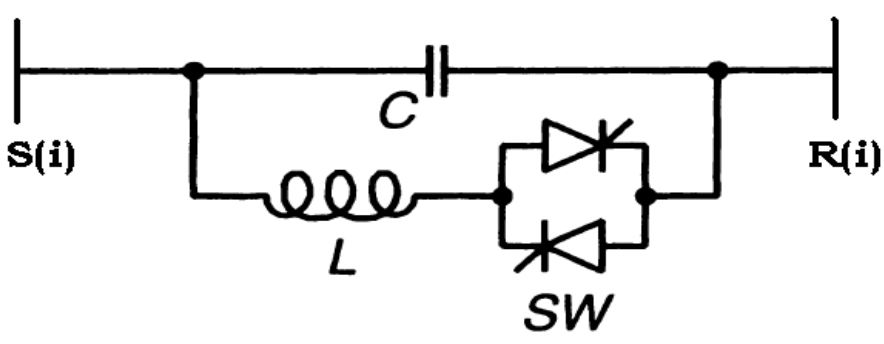

Fig. 1. TCSC Module

A TCR includes a pair of anti-parallel thyristors that are connected in series with an inductor. In a TCSC, a metal oxide varistor (MOV) along with a bypass breaker is connected in parallel to the fixed capacitor for overvoltage protection. A complete compensation system may be made up of several of these modules.

\section{2) UPFC Modelling}

The UPFC is the most versatile FACTS controllers with capabilities of voltage regulation, series compensation, and phase shifting. The UPFC is a member of the family of compensators and power flow controllers [8]. The latter utilizes the synchronous voltage source (SVS) concept to provide a unique comprehensive capability for transmission system control. The UPFC is able to control simultaneously or selectively all the parameters affecting the power flow 51 patterns in a transmission network, including voltage magnitudes and phases, and real and reactive powers. These basic capabilities make the UPFC the most powerful device in the present day transmission and control systems.

UPFC fig2.having connected UPFC, the receiving end always injects PBt-QBtto bus $j$, and sending end voltage maintain VEt in bus i.

According to the above, if UPFC is replaced by elements which are being neutral to the known bus parameters, power flow answers remain constant [8]. These elements should inject PBt-QBt to bus $\mathrm{j}$ and keep VEt at bus i. A load model together with a generator is capable of injecting PBt-QBt to bus $\mathrm{j}$ while maintaining VEt at bus $\mathrm{i}$. The UPFC Power world simulator model is shown in Fig. 2.

To define the appropriate placement of TCSC and UPFC, firstly the base load flow study is carried out for the data. Weak and strong buses are identified with the values of active and reactive power flows respectively. P, Q is computed and ranked. It is noted that TCSC should not be placed between two generator buses. The reason for selecting a 30-bus system is, only a small part of a very large transmission. 


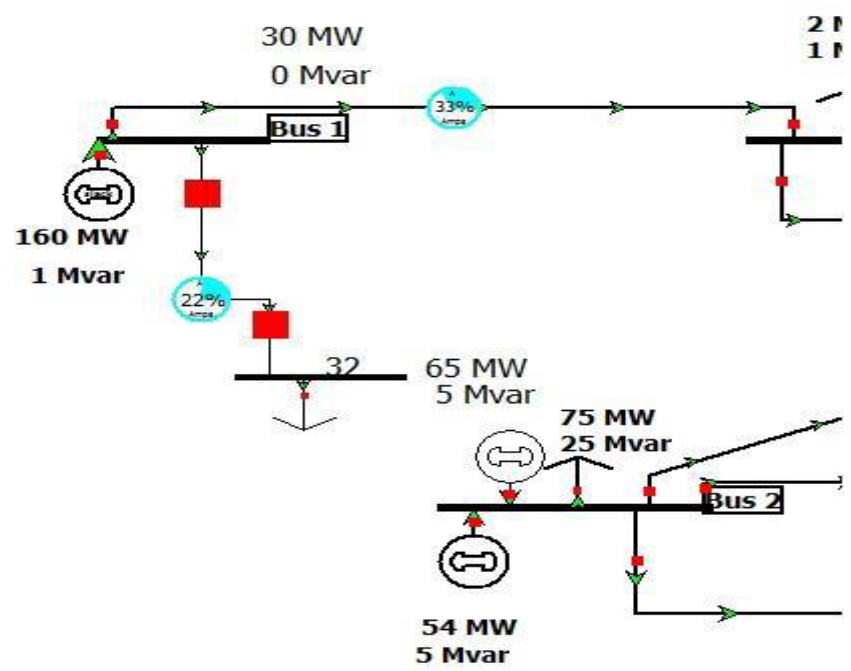

Fig. 2. UPFC modelling in Power World Simulator

\section{Demand Response}

In recent years the "smart grid" concept has emerged as a response to these challenges. The idea has been to use information exchange and communication technology to improve efficiency and distribution of power in electricity networks. The technology targets both producers and consumers where the electricity distribution and usage is optimized such that the grid can safely account for renewable energy source integration. The intermittent nature of renewable energy sources makes it difficult to accurately predict power production as it is closely tied to complex weather dynamics. The uncertainty in prognosis and high production variation accentuates the difficulties in maintaining safe system operation. This is one of many challenges electricity networks are facing when dealing with mass integration of renewable energy sources. An interesting solution aims at involving the electricity consumer by making them consume in a proactive manner, for example shift the consumption to periods when there is a need from the system to maintain balance. This concept is called Demand- Response (DR) and has become a popular solution. DR solutions have received a lot of attention in the scientific community.

\section{IV.CONCLUSION}

In the fast emerging restructured power system scenario, congestion management has become crucial task. Ever developing challenges and factors are forcing evolution of new techniques. In this paper we have discussed congestion management methods and techniques available for restructured system. An attempt has been made to encompass the emerging trends in Congestion Management however the list is not exhaustive.

\section{REFERENCES}

[1] Harish. R, Kannan. G “Congestion Management by Generator Rescheduling Using Genetic Algorithm Optimization Technique" An ISO 3297: 2007 certified organization.

[2] Kaushik K. Patel, Nilesh K. Patel "Generation Rescheduling For Congestion Management Using Relative Electrical Distance" Journal of Information, Knowledge and Research in Electrical Engineering Vol.02, Issue02.

[3] B.V. Manikandan, S.Charles Raja, P. Venkatesh, Manasarani Mandala "Comparative Study of Two Congestion Management Methods for the Restructured Power Systems" Journal of Electrical Engineering \& Technology Vol.6, No.3, Pp.302-310, 2011.

[4] N.S. Modi, Member IEEE, B.R. Parekh “Transmission Network Congestion In Deregulated Wholesale Electricity Market" Proceedings Of The International Multi Conference Of Engineers And Computer Scientists 2009 Vol. II, IMECS 2009, March 18 - 20, 2009 , Hong Kong.

[5] S.A.Khaparde "Power Sector Reforms and Restructuring in India" IEEE Conference Publications, 10 June 2004, Vol.2, Pp. 2328-2335.

[6] Avinash Swami, Electrical Engineer, "Transmission Congestion Impacts On Electricity Market: An Overview" International Journal Of Emerging Technology And Advanced Engineering, ISSN 2250 - 2459, ISO 9001:2008 Certified Journal, Vol.3, Issue 8, August 2013.

[7] R.M. Sasiraja, Dr. V. Suresh Kumar, S. Ponmani "Optimal Sizing And Sitting Of Distributed Generations For Relieving Congestion" International Journal Of Innovative Research In Science, Engineering And Technology, Vol.3, Special Issue 3, March 2014.

[8] Sujatha Balaraman, Dr. N. Kamaraj “Application Of Differential Evolution For Congestion Management In Power System” Published By Canadian Center Of Science And Education, Vol.4, No.8, August 2010.

[9] Hazra, A. K. Sinha, and Y. Phulpin, "Congestion management using generation rescheduling and/or load shedding of sensitive bu ses," in Proc. Third International Conference on Power Systems, 2009.

[10] Kunal M. Lokhande, Vinod G. Bhongade, Subbroto Dutt, "A review on Transmission Congestion management in restructured power system" International Journal on Recent and Innovation Trends in Computing and Communication,Vol.3, Issue 2.

[11] Shivam Sharma, Mohan Kashyap, Satish Kamal "Congestion Management in Deregulated Power Market - a Review" International Journal of Computer Applications (0975-8887), International Conference on Advances in Emerging Technology (ICAET 2016). 